\title{
Photodynamic Therapy of Prostate Cancer by Means of 5-Aminolevulinic Acid-Induced Protoporphyrin IX - In vivo Experiments on the Dunning Rat Tumor Model
}

\author{
Dirk Zaak $^{a, b}$ Ronald Sroka $^{b}$ Susanne Stocker ${ }^{b}$ Karl Bise $^{c}$ Michael Lein $^{d}$ \\ Michael Höppner ${ }^{b}$ Dominic Frimberger ${ }^{a, b}$ Peter Schneede ${ }^{a, b}$ \\ Oliver Reicha,b Martin Kriegmair $^{f}$ Ruth Knüchel ${ }^{\mathrm{e}}$ Reinhold Baumgartner ${ }^{b}$ \\ Alfons Hofstetter ${ }^{a, b}$ \\ aDepartment of Urology, b Laser Research Laboratory, ' Department of Neuropathology, Ludwig Maximilians \\ University, Munich; dDepartment of Urology, Charité University Hospital, Humboldt University, Berlin; \\ eInstitute of Pathology, University of Regensburg; fUrological Clinic, Planegg, Germany
}

\section{Key Words}

Photodynamic therapy · Prostate cancer ·

5-Aminolevulinic acid

\begin{abstract}
Objective: In order to expand the use of photodynamic therapy (PDT) in the treatment of prostate carcinoma (PCA), the aim of this study was to evaluate PDT by means of 5-aminolevulinic acid (5-ALA)-induced protoporphyrin IX (PPIX) in an in vivo tumor model. Methods: The model used was the Dunning R3327 tumor. First of all, the pharmacokinetics and the localization of PPIX were obtained using fluorescence measurement techniques. Thereafter, PDT using $150 \mathrm{mg} \mathrm{5-ALA/kg} \mathrm{b.w.} \mathrm{i.v.}$ was performed by homogenous irradiation of the photosensitized tumor (diode laser $\lambda=633 \mathrm{~nm}$ ). The tumors were resected 2 days post-PDT and the extent of the

D.Z. and R.S. contributed equally to the project and are to be considered as co-first authors.

This article contains parts of the inaugural thesis of M.H. at Ludwig Maximilians University, Munich.
\end{abstract}

necrosis was determined histopathologically. Results: The kinetics of PPIX fluorescence revealed a maximum intensity in the tumor tissue within 3 and $4.5 \mathrm{~h}$ post-application of 5-ALA. At this time, specific PPIX fluorescence could be localized selectively in the tumor cells. The PDTinduced necrosis ( $\mathrm{n}=18$ ) was determined to be $94 \pm$ $12 \%$ (range $60-100 \%$ ), while the necrosis of the controls ( $n=12$ ) differs significantly ( $p<0.01$ ), being less than $10 \%$. Conclusion: These first in vivo results demonstrate the effective potential of 5-ALA-mediated PDT on PCA in an animal model.

Copyright $@ 2004$ S. Karger AG, Basel

\section{Introduction}

Radical prostatectomy, external beam radiation and brachytherapy are considered to be the main treatment modalities in localized prostate cancer (PCA). However, severe bleeding, incontinence and impotence are considered to be the main side effects, especially in open surgery $[1,2]$. Therefore, efforts have been made to establish minimal invasive treatment modalities of PCA, like high-

Dirk Zaak, MD, Department of Urology-Grosshadern Ludwig Maximilians University Munich

Marchioninistrasse 15, DE-81377 Munich Germany)

Tel. +49897095 6723, Fax +49 8970956722

E-Mail Dirk.Zaak@uro.med.uni-muenchen.de 
intensity focused ultrasound or cryosurgical ablation [3, 4]. In addition, photodynamic therapy (PDT) has been proposed as a promising in situ treatment for localized PCA [5]. PDT is a technique using the interaction between an administered photosensitizing agent serving as a transient accumulation in cancerous tissue and light with an appropriate wavelength which is then absorbed by the photosensitizer. Consequently, this light-induced photochemical process causes a selective tissue necrosis. Recently, the effectiveness of several photodynamic agents in PDT on PCA was investigated in a number of experimental studies [6-8]. However, there was a major drawback because of the skin photosensitization caused by the most commonly used agents, for instance hematoporphyrin derivative (HPD) [9]. Therefore, a new generation of photosensitizers, which causes less skin reactions, is currently under intensive investigation in the treatment of a range of malignancies [10]. 5-Aminolevulinic acid (5ALA) is a precursor in the heme biosynthesis pathway. After undergoing a series of enzymatic catalyzed reactions, 5-ALA is metabolized to fluorescent protoporphyrin IX (PPIX), before being converted to photo-inactive heme. PPIX is the endogenous photosensitizer needed for the PDT, which accumulates temporarily in the tumor tissue after the exogenous application of 5-ALA [11].

Referring to this, there is lack of investigating the 5ALA-mediated PDT on an in vivo PCA model which is a prerequisite to motivate PDT of PCA into clinical trials. Therefore, the principal objective was to prove the selective tumor-destroying effect of 5-ALA-mediated PDT in an in vivo prostate tumor, using the R3327 DunningTumor model.

\section{Materials and Methods}

\section{In vivo Tumor Model}

The Dunning R3327 tumor was used as prostate tumor model [12]. Following standard cultivation of the tumor cell subline MatLy$\mathrm{Lu}, 1 \cdot 10^{5}$ cells were injected subcutaneously into the right upper thigh of anesthetized 2-month-old male Copenhagen rats (b.w. 200250 g; Charles River, Sulzfeld, Germany) [13].

The fluorescence measurements as well as the photodynamic therapies were performed when the tumors reached a size of approximately $5 \mathrm{~mm}$ in diameter (measured with calipers). In all experiments, the skin covering the tumor was removed and the bare tumor surface was exposed for measurement and illumination. In order to avoid uncontrolled light exposure (inducing side effects or photo bleaching), all experiments and preparations were performed in a darkened room.

The animals were anesthetized by a mask slipped over the nose for inhalation of a narcotic mixture containing isoflurane and oxygen (conc.: $1.5-2.5 \mathrm{vol} \%$ isoflurane; flowing rate: $0.51 / \mathrm{min}$; inhalation device: Titus with isoflurane Vaporisator 19.3; Dräger Medizintechnik, Lübeck, Germany). Before and after treatment, animals received food and water ad libitum. All experiments were approved by the appropriate institutional committee as well as by an external animal protection committee of the government.

\section{5-Aminolevulinic Acid}

5-ALA (medac GmbH, Wedel, Germany) was dissolved in 5.7\% sodium monohydrogen phosphate. A solution of $150 \mathrm{mg} / \mathrm{kg}$ b.w. of 5-ALA was applied intravenously by means of a cannula inserted into the right vena femoralis of the hosts.

\section{Fluorescence Measurements}

In order to evaluate the efficacy of a 5-ALA-mediated PDT, it is an indispensable prerequisite to get a secure time range for PDT and the verification of the selective accumulation of PPIX within the tumor cells. Therefore, both the pharmacokinetic and localization of 5-ALA-induced PPIX was examined prior to PDT.

PPIX fluorescence was excited by an incoherent light source emitting light in the spectral range of $\lambda=385-440 \mathrm{~nm}$ (Karl Storz $\mathrm{GmbH}$, Tuttlingen, Germany) [14]. The excitation light was guided by a flexible transmission system to a conventional rigid cystoscope positioned in front of the bare tumor surface to illuminate a spot size of $2-3 \mathrm{~mm}$ in diameter. The fluorescence light was guided through the telescope optic of the cystoscope. An optical beam splitter covering the ocular reflected the fluorescence light, which was then coupled into a flexible fiber for transfer to an optical multichannel analyzer system (SI-Spectroscopy \& Imaging GmbH, Germany). Fluorescence emission spectra were recorded in the spectral range between $\lambda=500$ and $750 \mathrm{~nm}$.

In such a way, PPIX fluorescence spectra were obtained from the MatLyLu tumors of 7 animals. The spectra were taken at intervals of 15-30 min up to a period of $8 \mathrm{~h}$ after application of 5-ALA. Immediately before injection of 5-ALA, the background spectrum of the tumor tissue intrinsic fluorochromes was obtained.

To calculate the PPIX fluorescence kinetics, the spectra of each tumor were normalized due to their fluorescence intensity at $\lambda=$ $605 \mathrm{~nm}$, where no PPIX emission occurs. After subtraction of the background intensity, the fluorescence intensity of the main PPIX emission band at $\lambda=635 \mathrm{~nm}$ was plotted as a function of the time post-injection for each tumor.

The examination of the localization of the PPIX fluorescence was performed on an additional three tumors, which were harvested at the time of maximum PPIX fluorescence due to the fluorescence kinetic results and prepared for frozen sections. The frozen slides were examined using fluorescence microscopic techniques and the adjacent slides were HE-stained to correlate the fluorescence distribution pattern with the histopathology using conventional light microscopy.

\section{Photodynamic Therapy}

PDT was performed by a diode laser (CeraLas PDT 633, CeramOptec GmbH, Bonn, Germany) emitting at a wavelength of $\lambda=633 \mathrm{~nm}$. The light was transmitted via a flexible micro lens ended fiber to the target tissue. In such way a homogenous light intensity distribution on an area of $1.5 \mathrm{~cm}^{2}$ covering the tumor tissue and a border of about $5 \mathrm{~mm}$ was obtained. The irradiance was set to $100 \mathrm{~mW} / \mathrm{cm}^{2}$ and measured immediately before and after each illumination by means of a calibrated power meter. To obtain an irradiation of $100 \mathrm{~J} / \mathrm{cm}^{2}$, each tumor was illuminated for $1,000 \mathrm{~s}$. 
Fig. 1. PPIX fluorescence kinetic of the main PPIX fluorescence emission band at $\lambda=635 \mathrm{~nm}$ of a single Dunning R3327 tumor (insert: PPIX fluorescence spectrum).

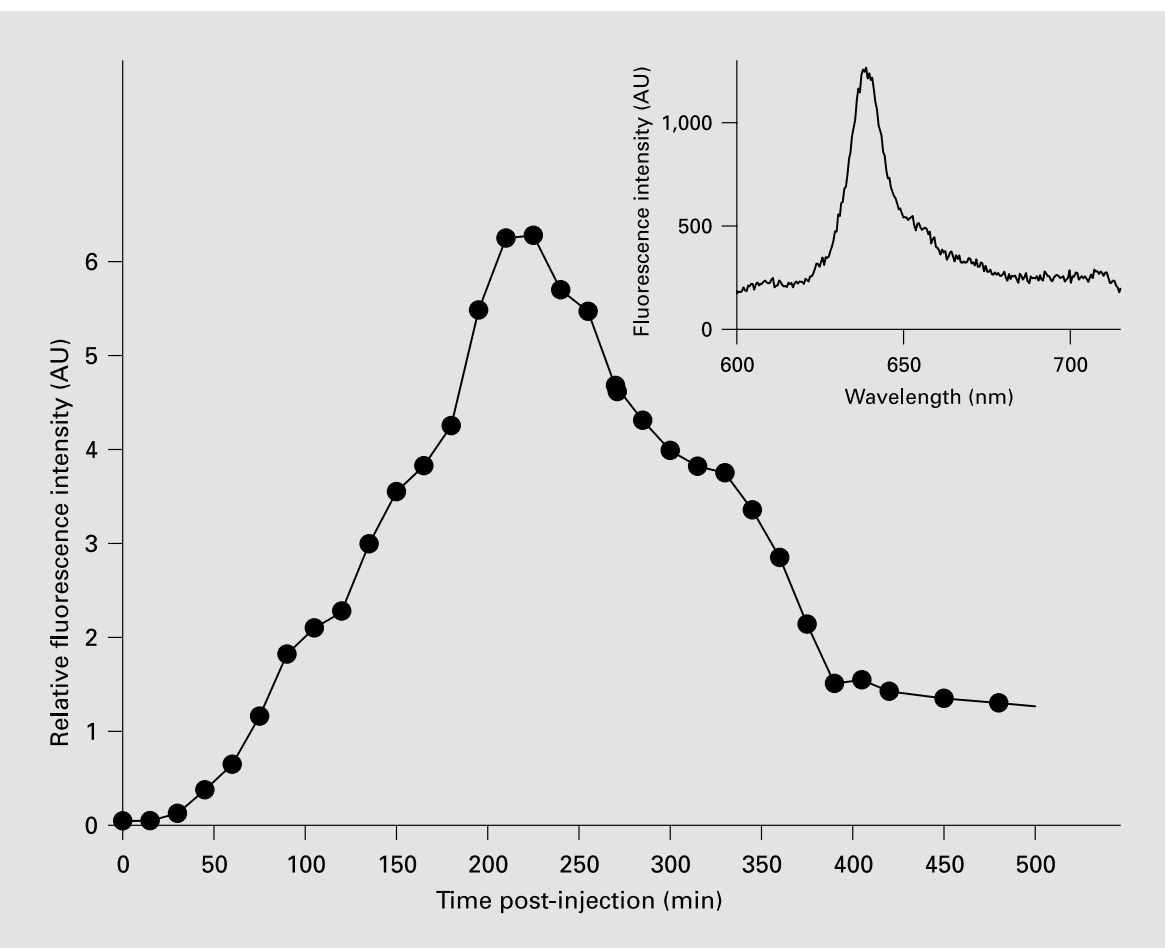

According to the accumulation time derived from the PPIX fluorescence kinetics measurements, PDT was performed on 18 animals (group IV). The size of the bare tumor was measured with a caliper immediately before photodynamic irradiation.

The tumors were harvested $48 \mathrm{~h}$ post-PDT and again their sizes were measured using calipers. Afterwards the tumors were prepared in serial sections for HE staining to determine the size of necrotic area histopathologically.

The tumor sections were inspected and the diameter of the total tumor area as well as the tumor necrotic sector were both measured in two perpendicular dimensions by means of an intraocular caliper of the light microscope (magnification $\times 40$ ). The size of the areas were calculated, assuming an elliptical shape according to the ellipse formula $(\mathrm{A}=\mathrm{a} \cdot \mathrm{b} \cdot \pi)$. The percentage of necrosis for each individual tumor was calculated by the ratio of necrotic area divided by the total tumor area.

Twelve animals, bearing the Dunning R3327 tumor at the same location as the 18 PDT-treated animals, served as controls. After undergoing identical preparations they received the following treatment: (group I) neither 5-ALA nor light, (group II) only 5-ALA no light, (group III) only light no 5-ALA. After 2 days the tumor tissue was harvested and the histological examination followed according to the PDT-treated animals (group IV).

\section{Statistical Analysis}

Average, standard deviation and the range of the percentage of necrotic areas were calculated using standard software (MS-Excel 2000). The effect of PDT on the tumors as compared to the controls was proven by means of the Mann-Whitney test and the Wilcoxon test at a significance of $\mathrm{p}<0.05$.

\section{Results}

\section{Fluorescence Investigation}

A typical fluorescence spectrum showing its prominent emission band at $\lambda \simeq 635 \mathrm{~nm}$ and $\lambda \simeq 705 \mathrm{~nm}$ is depicted in the inset of figure 1, indicating the evidence for the detection of PPIX. The fluorescence intensity kinetic due to the main peak at $\lambda \simeq 635 \mathrm{~nm}$ of 5 -ALA-induced PPIX exemplified on one single Dunning tumor is represented in figure 1. After a slow increase in the fluorescence intensity of PPIX within the first $60 \mathrm{~min}$, the formation of fluorescing PPIX becomes faster to reach a maximum fluorescence intensity between 3 and $4 \mathrm{~h}$ post-injection of 5-ALA. Afterwards, fluorescence decreased, indicating the clearance of PPIX from the tumor tissue, where $8 \mathrm{~h}$ post-5-ALA application only a weak fluorescence could be measured within the tumor tissue. In all experiments $(\mathrm{n}=$ 7) performed, the time range to reach the maximum PPIX fluorescence intensities was found to be between 3 and $4.5 \mathrm{~h}$ post-injection of 5-ALA.

The localization of the PPIX fluorescence is demonstrated in the fluorescence pattern of a frozen section and its corresponding HE-stained section in figure $2 a, b$. The origin of the red PPIX fluorescence can be attributed explicitly to the tumor cells, while green autofluorescence 

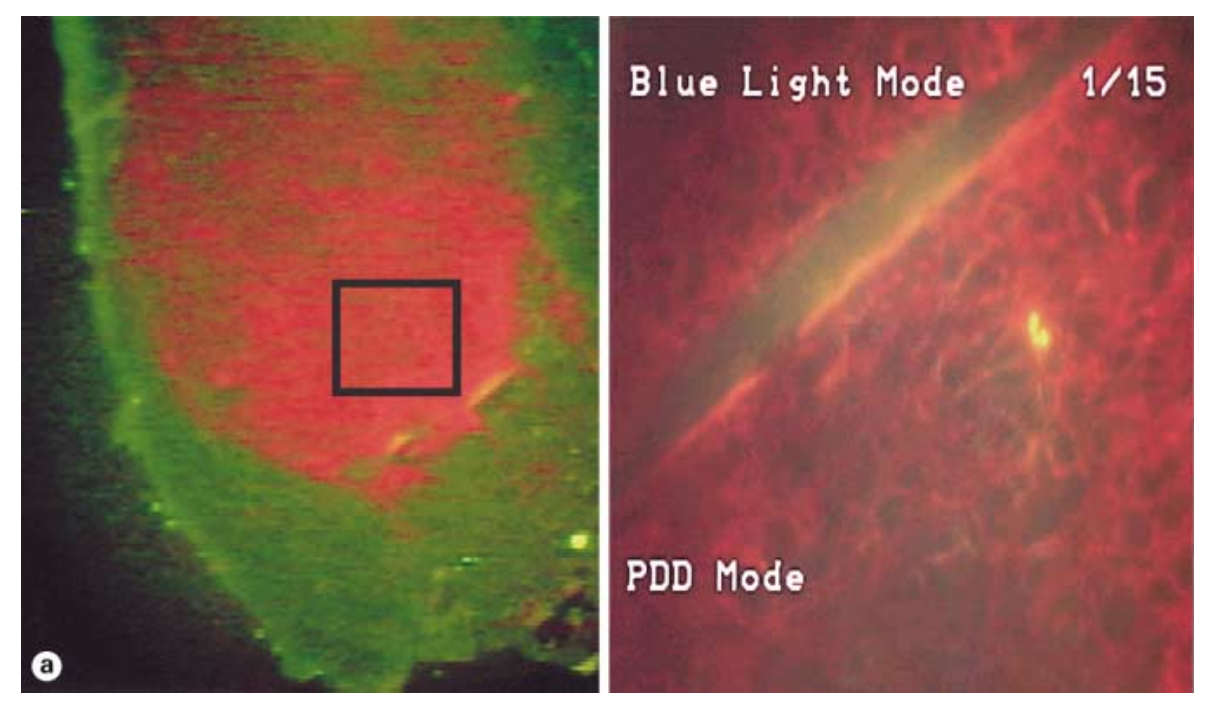

Fig. 2. Fluorescence pattern (a) of the frozen section (overview and $10 \times$ magnifications) and the corresponding HE-stained slide (b) of a Dunning R3327 tumor (overview and $500 \times$ magnification). The red PPIX fluorescence (a) can be attributed explicitly to the tumor cells while green autofluorescence is obtained from adjacent normal connective subcutaneous tissue.
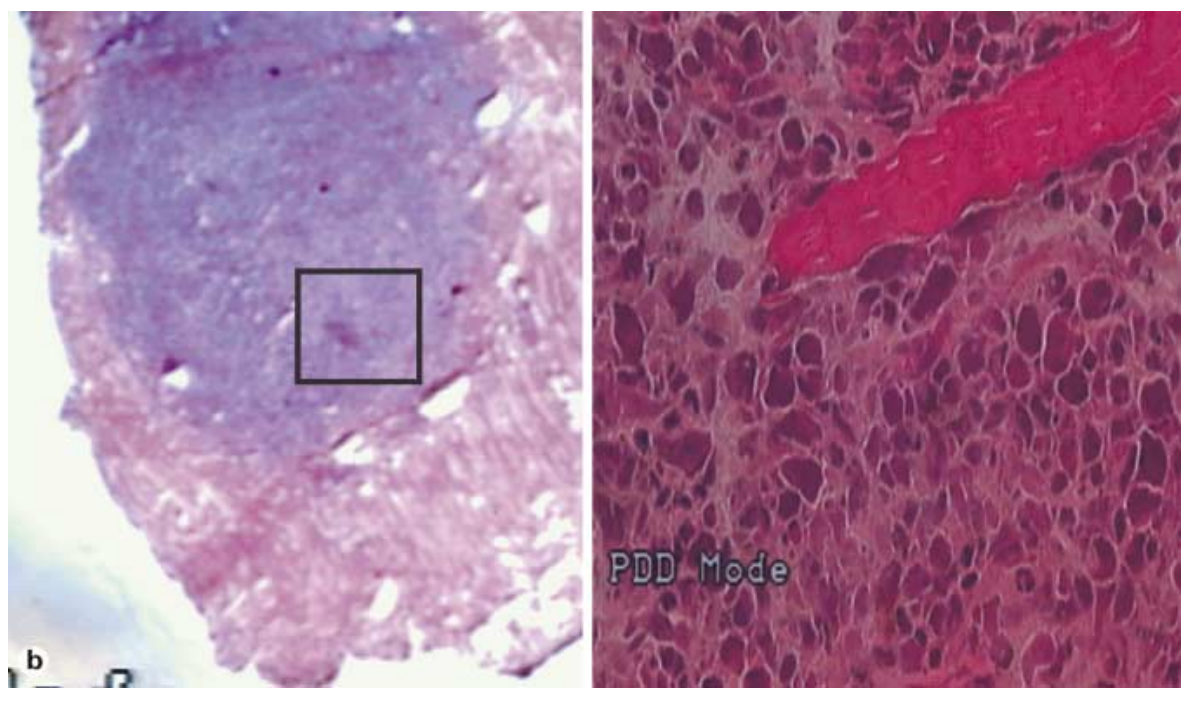

is obtained from adjacent normal connective subcutaneous tissue.

\section{Photodynamic Therapy}

The PDT was well tolerated from each animal, especially no cutaneous photosensitization was observed after application of 5-ALA. The gross inspection of the tumor growth measured by calipers at the time of tumor resection showed an increase of the tumor diameter by a factor of 2.5 in case of the controls (groups I-III), while the tumors of the PDT-treated group (IV) were of edematous and viscid consistence with an increase of macroscopic growth $(\mathrm{p}=0.004)($ table 1$)$.

The histopathological investigation showed spheroidal tumors with an outer layer of vital cells (layer thickness of

Photodynamic Therapy of Prostate Cancer
Table 1. Macroscopic tumor growth before and after PDT (controls: 6 animals, which received neither 5-ALA nor light)

\begin{tabular}{|c|c|c|c|c|}
\hline Group & & $\begin{array}{l}\text { Tumor volume } \\
\text { before PDT } \\
\mathrm{mm}^{3}\end{array}$ & $\begin{array}{l}\text { Tumor volume } \\
\text { after PDT } \\
\mathrm{mm}^{3}\end{array}$ & Change \\
\hline \multirow{4}{*}{$\begin{array}{l}\text { PDT } \\
(n=18) \\
\text { Controls } \\
(n=6)\end{array}$} & Average & 82.17 & 52.41 & \multirow[t]{2}{*}{$-416 \% *$} \\
\hline & Range & $18-224$ & $12-168$ & \\
\hline & Average & 41.33 & 116.50 & \multirow[t]{2}{*}{$+226.6 \%$ \# } \\
\hline & Range & $12-70$ & $28-200$ & \\
\hline
\end{tabular}

${ }^{*} \mathrm{p}=0.004 ;{ }^{*} \mathrm{p}=0.028$

Urol Int 2004;72:196-202 

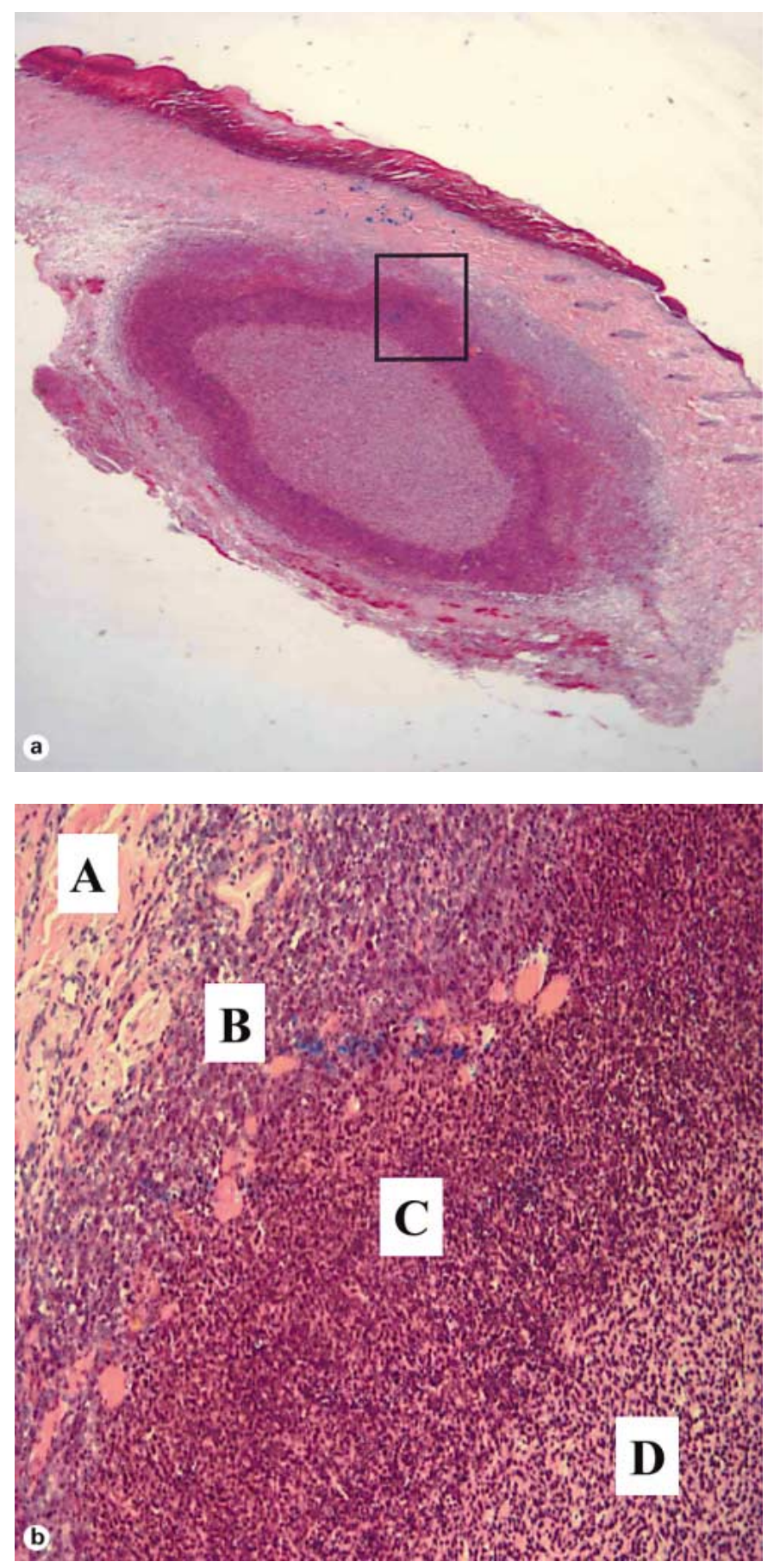

Fig. 3. a Histopathologic slide of a $90 \%$ necrosis of the Dunning R3327 tumor. HE-stained overview and $50 \times$ magnification. b Enlargement from different zones of the tumor: (A) surrounding subepidermal stromal tissue with lymphocytic infiltrate; (B) small zone of vital tumor cells; (C) dark area of mixed apoptosis and necrosis, and (D) central apoptotic cells.
Table 2. List of induced necrosis with respect to each treatment group

\begin{tabular}{lccccc}
\hline Groups & Animals & $\begin{array}{l}\text { Irradiation } \\
\mathrm{J} / \mathrm{cm}^{2}\end{array}$ & $\begin{array}{l}\text { 5-ALA } \\
\mathrm{mg} / \mathrm{kg} \text { b.w. }\end{array}$ & \multicolumn{2}{c}{$\begin{array}{l}\text { Part of necrosis, \% } \\
\text { average } \pm \text { SD range }\end{array}$} \\
\hline I & 6 & 0 & 0 & $6 \pm 4$ & $0-10$ \\
II & 3 & 0 & 150 & $8 \pm 3$ & $0-10$ \\
III & 3 & 100 & 0 & $7 \pm 4$ & $0-10$ \\
IV & 18 & 100 & 150 & $94 \pm 12$ & $60-100$ \\
\hline
\end{tabular}

Group I: neither 5-ALA nor light; group II: only 5-ALA no light; group III: only light no 5-ALA; group IV: PDT.

2-7 cells) which are demonstrated in figure 3 . The center of the tumor mainly shows necrosis and typically includes a distinct zone of apoptosis close to the vital cell layers, as seen by a circular accumulation of apoptotic bodies adjacent to the necrosis zone in cross sections. In contrast, all tumors of the control groups showed exclusively vital cells with insular nests of intratumoral necrosis $(<0.5 \mathrm{~mm})$.

The results of the histopathologic quantification of the necrotic part of the tumors with respect to the treatment protocol are listed in table 2. The part of the necrosis in the PDT-treated tumors was calculated to be in an average of $94 \pm 12 \%$ ranging from $60 \%$ up to $100 \%$, while the controls presented necrosis of maximum 10\% (average: $6 \%$ group I; $8 \%$ group II; $7 \%$ group III) 2 days after the procedure took place. While the percentage of necrosis differed significantly from the controls $(p<0.01)$, no significant difference could be calculated from the three control groups.

\section{Discussion}

So far, only a few experimental and clinical studies have investigated the effective potential of PDT as a treatment modality of PCA. In the early 1980s, McPhee et al. [16] and Gonzalez et al. [15] demonstrated the efficacy of PDT using HPD in the Dunning tumor model. In addition, Henry and Isaacs [17] showed that the combination of an alkylating chemotherapeutic agent like RSU-1164 and PDT using HPD synergistically produced a greater retardation in the growth of Dunning tumors in Copenhagen rats. In 1990, Windahl et al. [5] reported on 2 patients with PCA treated by transurethral PDT by means of HPD. Nevertheless, HPD and Photofrin have two main limitations [18], i.e. (1) they have a weak light absorption 
at wavelength above $600 \mathrm{~nm}$, while light at longer wavelengths penetrates farther into tissue, and (2) they cause prolonged cutaneous photosensitivity. These properties provided incentives for developing new photosensitizers. Recently, Nathan et al. [19] treated 14 patients with local recurrence of PCA after radiotherapy by PDT using meso-tetra- $m$-hydroxyphenyl-chlorin (mTHPC) as a salvage treatment. They concluded that PDT using this agent might be a new therapeutic option that could be suitable for organ-confined PCA. Currently, further photosensitizers or precursors, like 5-ALA, are under intensive experimental and clinical investigation. 5-ALA does have several advantages - it has a high selectivity in rapidly proliferating cells, it is rapidly eliminated from the body (within $24 \mathrm{~h}$ ), it is well tolerated without cutaneous photosensitization and it can be applied repeatedly without cumulative toxicity [20]. Therefore, PDT using 5ALA, with its selective destruction of target tissues could be an alternative in the treatment of localized PCA. In vitro experiments by Chakrabarti et al. [21], using two different PCA cell lines (LNCaP, PC-3) showed that 5-ALAmediated PDT might be effective in killing PCA cells. Recently, we demonstrated a significant non-thermal necrosis in the edematous tissue of normal canine prostates following 5-ALA-mediated PDT. The necrosis was strictly limited to the epithelial tissue compared to the normal stroma tissue [22]. These findings were consistent with the results of Johnson et al. [23], who reported about significant necrosis in normal canine prostates after PDT with 5-ALA, compared to unsensitized animals, too. These promising data provided the background for the present study to prove the effect of a 5-ALA-mediated PDT using a variant of the Dunning R3227 tumor in vivo. This adenocarcinoma was chosen because of its close similarities with human PCA with regard to its behavior under hormonal therapy, chemotherapy and radiation therapy [24]. Recently, Lein et al. [25] demonstrated that orthotopic implantation of tumor cells may be needed for accurate assessment of the metastatic potential. However, the present study evaluates the efficacy of local tumor control and not of metastatic potential. Therefore, with regard for accessibility to experimental manipulation of the PDT, we decided to prove the selective local tumor destroying effect of 5-ALA-mediated PDT in a heterotopic model. Nevertheless, this might be a drawback of the study. Due to the heterotopic approach, we were not able to study PDT effects on the benign prostate or the adjacent tissue. However, recently, we evaluated the potential of 5-ALA-mediated PDT in canine prostates. The necrosis was strictly limited to the epithelial tis- sue of the prostates and no serious local complications (rectal ulcer, voiding dysfunction, incontinence) were observed [22].

The in vivo fluorescence investigations in the present study demonstrated the capability of MatLyLu cells to metabolize an exogenous supply of 5-ALA into PPIX which is indicated by the suitable PPIX emission spectrum. Since an intravenous injection was applied, the fluorescence pattern of the frozen section circumstantiates the assumption of an increased activity of the heme biosynthetic pathway in this PCA cell line compared to the surrounding tissue. This results in a transient and selective accumulation of the photosensitizer PPIX in the MatLyLu tumor with maximum fluorescence intensity within $3-4.5 \mathrm{~h}$ post-injection. The pharmacokinetic is comparable to results determined in several other organs in which 5-ALA-mediated PDT is under clinical investigation [26].

Following PDT, the histological inspection of the tumors resulted in a response of an average of $94 \%$ destroyed tumor tissue. In some cases a shell consisting of 2-7 layers of vital cells demarcated the MatLyLu tumor from the adjacent normal tissue. These cells most likely proliferated after PDT had been performed, since the cells are adjacent to the supplying vasculature. Several factors might account for the differences in the extent of the cell damage observed after PDT, e.g. photosensitizer concentration, irradiation, oxygen. However, the present study was not designed to perform a dose-response investigation examining the impact of various 5-ALA concentrations, or different light doses. Further studies will asses these variables.

In the inner part of the spheroidal tumors, necrotic as well apoptotic cells could be observed. While the necroses were the result of immediate PDT cell killing due to an optimum combination of PPIX concentration, optimum light excitation and sufficient intracellular oxygen support, it could be assumed that the apoptotic cells were the result of insufficient PDT most likely due to hypoxia and a lower PPIX concentration [27, 28].

The results demonstrate a high effectiveness of 5-ALAmediated PDT in the Dunning R3327 prostate adenocarcinoma. With regard to the macroscopic and microscopic findings, the effects of PDT differed significantly from the controls which exhibited only a low rate of spontaneous necrosis. The comparison of the macroscopic measurements of the tumor sizes by calipers pre-PDT and pretumor resection showed effective tissue reaction due to PDT while the tissue growth of the controls progressed continuously. 


\section{Conclusion}

In conclusion, this study suggests that the injection of exogenous 5-ALA induced a selective PPIX accumulation in this in vivo tumor model. Performing PDT after the determined incubation time results in effective killing of PCA in the Dunning R3327 tumor model when suitable parameters are used.

\section{Acknowledgement}

Grant No. 118 (FöFoLe) Ludwig Maximilians University Munich for financial support. The authors would appreciate to thank $\mathrm{M}$. Heide for his technical assistance and Dr. Heston (Memorial SloanKettering Cancer Center, New York, N.Y.) providing the cell line.

\section{References}

1 Schwartz K, Bunner S, Bearer R, Severson RK: Complications from treatment for prostate carcinoma among men in the Detroit area. Cancer 2002;95:82-89.

2 Heinzer H, Graefen M, Noldus J, Hammerer $\mathrm{P}$, Huland $\mathrm{H}$ : Early complication of anatomical radical retropubic prostatectomy: Lessons from a single-center experience. Urol Int 1997; 59:30-33.

3 Chaussy C, Thuroff S: Results and side effects of high-intensity focused ultrasound in localized prostate cancer. J Endourol 2001;15:437440.

4 Long JP, Bahn D, Lee F, Shinohara K, Chinn DO, Macaluso JN Jr: Five-year retrospective, multi-institutional pooled analysis of cancerrelated outcomes after cryosurgical ablation of the prostate. Urology 2001;57:518-523.

5 Windahl T, Andersson SO, Lofgren L: Photodynamic therapy of localised prostatic cancer. Lancet 1990;336:1139.

6 Chang SC, Buonaccorsi G, MacRobert A, Bown SG: Interstitial and transurethral photodynamic therapy of the canine prostate using meso-tetra-( $m$-hydroxyphenyl) chlorin. Int $\mathbf{J}$ Cancer 1996;67:555-562.

7 Momma T, Hamblin MR, Wu HC, Hassan T: Photodynamic therapy of orthotopic prostate cancer with benzoporphyrin derivative: Local control and distant metastasis. Cancer Res 1998;58:5425-5431.

8 Pantelides ML, Whitehurst C, Moore JV, King TA, Blacklock NJ. Photodynamic therapy for localized prostatic cancer: Light penetration in the human prostate gland. J Urol 1990;143: 398-401.

9 Wilson BC: Photodynamic therapy for cancer: Principles. Can J Gastroenterol 2002;16:393396.

10 Peng Q, Berg K, Moan J, Kongshaug M, Nesland JM: 5-Aminolevulinic acid-based photodynamic therapy: Principles and experimental research. Photochem Photobiol 1997;65:235251.
11 Hua Z, Gibson SL, Foster TH, Hilf R: Effectiveness of $\delta$-aminolevulinic acid-induced protoporphyrin as a photosensitizer for photodynamic therapy in vivo. Cancer Res 1995;55: 1723-1731.

12 Isaacs JT, Isaacs WB, Feitz WF, Scheres J: Establishment and characterization of seven Dunning rat prostatic cancer cell lines and their use in developing methods for predicting metastatic abilities of prostatic cancers. Prostate 1986;9:261-281.

13 Lein M, Koenig F, Misdraji J, McDougal WS, Jung K, Loening SA, Hassan T, Ortel B: Laserinduced hyperthermia in rat prostate cancer: Role of site of tumor implantation. Urology 2000;56:167-172.

14 Zaak D, Kriegmair M, Stepp H, Baumgartner R, Oberneder R, Schneede P, Corvin S, Frimberger D, Knüchel R, Hofstetter A: Endoscopic detection of transitional cell carcinoma with 5aminolevulinic acid: Results of 1,012 fluorescence endoscopies. Urology 2001;57:690-694.

15 Gonzalez S, Arnfield MR, Meeker BE, Tulip J, Lakey WH, Chapman JD, McPhee MS: Treatment of Dunning R3327-AT rat prostate tumors with photodynamic therapy in combination with misonidazole. Cancer Res 1986;46: 2858-2862.

16 McPhee MS, Thorndyke CW, Thomas G, Tulip J, Chapman D, Lakey WH: Interstitial applications of laser irradiation in hematoporphyrin derivative-photosensitized Dunning R3327 prostate cancers. Lasers Surg Med 1984; 4:93-98.

17 Henry JM, Isaacs JT: Synergistic enhancement of the efficacy of the bioreductively activated alkylating agent RSU-1164 in the treatment of prostatic cancer by photodynamic therapy. $\mathrm{J}$ Urol 1989; 142:165-170.

18 Dougherty TJ, Gomer CJ, Henderson BW, Jori G, Kessel D, Korbelik M, Moan J, Peng Q: Photodynamic therapy. J Nat Cancer Inst 1998;90:889-905.

19 Nathan TR, Whitelaw DE, Chang SC, Lees WR, Ripley PM, Payne H, Jones L, Parkinson MC, Emberton M, Gillams AR, Mundy AR, Bown SG: Photodynamic therapy for prostate cancer: A phase I study treating recurrence after radiotherapy. J Urol 2002;168:14271432.
20 Peng Q, Warloe T, Berg K, Moan J, Kongshaug M, Giercksky KE, Nesland JM: 5-Aminolevulinic acid-based photodynamic therapy. Cancer 1997;79:2282-2308.

21 Chakrabarti P, Orihuela E, Egger N, Neal DE, Gangula R, Adesokun A, Motamedi M: $\delta$-Aminolevulinic acid-mediated photosensitization of prostate cell lines: Implication for photodynamic therapy of prostate cancer. Prostate 1998;36:211-218.

22 Sroka R, Zaak D, Höppner M, Muschter R, Knüchel R, Perlmutter A, Hofstetter A: In vivo investigations of photodynamic therapy by means of 5-ALA induced PPIX on canine prostates. Med Laser Appl 2003;18:87-90.

23 Johnson S, Motamedi M, Egger N, Pow-Sang M, Orihuela E, Anderson K, Warren MM: Photosensitizing the canine prostate with 5-aminolevulinic acid: A new laser prostatectomy? J Urol Suppl 1995; 153:298.

24 Lubaroff DM, Canfield L, Feldbush TL, Bonney WW: R3327 adenocarcinoma of the Copenhagen rat as a model for the study of the immunologic aspects of prostate cancer. J Natl Cancer Inst 1977;58:1677-1689.

25 Lein M, Koenig F, Misdraji J, McDougal WS, Jung K, Loening SA, Hasan T, Ortel B: Laserinduced hyperthermia in rat prostate cancer: Role of site of tumor implantation. Urology 2000;56:167-172.

26 Rick K, Sroka R, Stepp H, Kriegmair M, Huber RM, Jacob K, Baumgartner R: Pharmacokinetics of 5-aminolevulinic acid-induced protoporphyrin IX in skin and blood. J Photochem Photobiol B 1997;40:313-319.

27 Oleinick NL, Morris RL, Belichenko I: The role of apoptosis in response to photodynamic therapy: What, where, why, and how? Photochem Photobiol Sci 2002;1:1-21.

28 Godar D: Light and death: Photons and apoptosis. J Invest Dermatol Symp Proc 1999;4:1723 